\title{
PRUEBA DE DIGESTIBILIDAD IN VITRo CON DIFERENTES PROPORCIONES DE SALIVA ARTIFICIAL Y FLORA MICROBIANA EN ALPACAS
}

\author{
Luisa Leyva ${ }^{1}$, Teresa Arbaiza F. $^{2}$, Felipe San Martín H. ${ }^{2}$ y Fernando Carcelén C. $^{2}$
}

In vitro digestibility test with different artificial saliva proportions in alpacas

The objective of this study was to determinate the correct relationship between artificial spittle and rumen fluid in alpaca forage using the in vitro digestibility technique. Three fistualted 4 years old, $50 \mathrm{~kg}$. male huacayas were fed high (Rye grass of 3-4 weeks growth), medium (rye grass of 6-8 weeks growth) and low quality (oat straw) forages respectively, with alfalfa hay was used as the standard sample. Each of the 3 forages was treated with artificial saliva:rumen fluid (T) as follows: $T_{1} 2: 1 ; T_{2} 4: 1 ; T_{3}$ $6: 1 ; \mathrm{T}_{4} 8: 1$ and the in vitro digestibility of dry matter (IVDMD) was evaluated for each treatment. A randomized complete block design ( $\mathrm{A} \times \mathrm{B}$ ) was used, with $\mathrm{A}$ being the various artifical spittle: rumen fluid concentrations and $B$ forage quality, and the results evaluated using analysis of variance and least significant difference (LSD) statistics. No significant difference was found in IVDMD for all four treatments in the high and medium quality forages $(P>0.05)$ with $\mathrm{T}_{1}, \mathrm{~T}_{2}, \mathrm{~T}_{3}$ and $\mathrm{T}_{4}$ yielding 87.2, 84.5, 87.1 and $84.4 \%$ for high and $85.7,86.6,83.0$ and $79.2 \%$ for medium respectively. Likewise, for the low quality forage, $T_{1}, T_{2}$ and $T_{3}$ yielded statistically insignificant results of $54.3,52.3$ and $53.3 \%$, while $\mathrm{T}_{4}$ produced a significant difference $(\mathrm{P}<0.01)$ at $40.4 \%$ IVDMD. The results of all 4 treatments on all 3 forage types, yielded only one case of reduced dry matter digestibility produced by the high (8:1) proportion of artificial spittle to rumen fluid in $\mathrm{T}_{4}$ on low quality forage.

Key words: In vitro digestibility, artificial saliva, alpacas

El presente estudio se realizó con la finalidad de determinar la relación adecuada de Saliva artificial : licor ruminal en alpacas, aplicando la técnica de digestibilidad in vitro. Se utilizó tres alpacas machos con fístula ruminal de la variedad Huacaya, con un peso y edad promedio de $50 \mathrm{~kg}$. y 4 años, respectivamente. Los forrajes que se utilizaron fueron de tres diferentes calidades: alta (rye grass 3-4 semanas); media (rye grass 6-8 semanas) y baja ( paja de avena), el heno de alfalfa fue la muestra patrón. Los tratamientos de la relación de saliva artificial : licor ruminal fueron: $\mathrm{T}_{1} 2: 1, \mathrm{~T}_{2} 4: 1$, $\mathrm{T}_{3} 6: 1$ y $\mathrm{T}_{4} 8: 1$. Los que fueron aplicados a cada forraje. El parámetro a evaluarse fue la digestibilidad in vitro de la materia seca (DIVMS). El diseño experimental fue el irrestricto al azar con arreglo factorial $(\mathrm{A} \times \mathrm{B})$, siendo el factor $\mathrm{A}$, las concentraciones de saliva artificial y licor ruminal y el factor $B$, la calidad de forraje. Los datos se analizaron por el análisis de varianza y para la diferencia entre tratamientos se uso el análisis de diferencias mínimas significativa (LSD). La DIVMS en el forraje de alta calidad para los tratamientos ya mencionados, no se halló diferencia estadística significativa $(P>0.05$, siendo las siguientes $87.2 \%, 84.5 \% 87.1 \%, 84.4 \%$ para $\mathrm{T}_{1}, \mathrm{~T}_{2}, \mathrm{~T}_{3}$ y $\mathrm{T}_{4}$ respectivamente.

\footnotetext{
1 Práctica privada

${ }^{2}$ UNMSM-FMV-IVITA. E-mail: dl70032@unmsm.edu.pe
} 
Para el forraje de mediana calidad no se hallo diferencia estadística significativa ( $P>0.05)$ siendo la DIV $85.7 \%, 86.6 \%, 83 \%, 79.2 \%$ para $\mathrm{T}_{1}, \mathrm{~T}_{2}, \mathrm{~T}_{3}$ y $\mathrm{T}_{4}$, respectivamente. Para el forraje de baja calidad se halló diferencia estadística significativa $(\mathrm{P}<0.01)$ entre el $\mathrm{T}_{4}$ (40.4\%) con los otros tratamientos, $\mathrm{T}_{1}, \mathrm{~T}_{2}$ y $\mathrm{T}_{3}(54.3 \%, 52.3 \%, 53.3 \%)$. Se concluye que la alta relación de saliva artificial : licor ruminal (T4) afectó al forraje de baja calidad. Pudiéndose usar relaciones del $\mathrm{T}_{1}$ al $\mathrm{T}_{3}$ sin que afecte la estimación de la digestibilidad de la materia seca.

Palabras clave: Digestibilidad in vitro, saliva artificial, alpacas.

\section{Tint butereror}

Dentro del amplio campo de la fisiología de la digestión, la saliva cumple un rol importante en la bioquímica del primer y segundo compartimento del estómago tanto por el volumen secretado como por su composición. La saliva es una solución tampón de fosfato y bicarbonato, proporciona un medio favorable a los microorganismos del primer y segundo compartimento del estómago, impidiendo bajas del $\mathrm{pH}$ ruminal, por acción de los ácidos grasos volátiles, lo que dificultaría la producción y la absorción de los mismos (Cunningham, 1995).

Bajo concentraciones similares de los ácidos grasos volátiles (AGV), el rumen retículo de los ovinos tiene valores de $\mathrm{pH}$ menores que los de la alpaca, debido a una mejor capacidad tamponante de esta última. Este hecho permite al camélido una mayor producción bacteriana debido a que los microorganismos del estómago desarrollan mejor a pH cercanos a la neutralidad (Vallenas, 1970; San Martín y Bryant, 1987).

Las pruebas de digestibilidad in vitro han sido desarrolladas desde los años sesenta (Tilley y Terry, 1963), y simulan la digestibilidad del tracto digestivo de los rumiantes. Sin embargo está técnica no ha sido adaptada a las características digestivas de los Camélidos, que como se señala tienen una diferente capacidad tamponante de los compartimentos ly 2.

El presente trabajo tiene como finalidad establecer la proporción óptima de saliva artificial: licor ruminal específica para las alpacas, con el fin de adaptar las técnicas para la estimación de la digestibilidades in vitro en esta especie.

El estudio se realizó en el Laboratorio de Bioquímica, Nutrición y Alimentación Animal, de la Facultad de Medicina Veterinaria de la Universidad Nacional Mayor de San Marcos.

Se utilizaron tres alpacas machos con fístula ruminal de variedad Huacaya, con un peso y edad promedio de $50 \mathrm{Kg}$ y 4 años, respectivamente. Los animales recibieron una dieta a base de chala, concentrado y agua ad libitum para lograr la adaptación de la micloflora ruminal a los forrajes a experimentar.

Las muestras fueron colectados en la Estación Experimental IVITA -El Mantaro, y enviados a Lima para su posterior análisis. Los forrajes evaluados fueron: Rye grass 3-4 semanas de edad, Rye grass 6-8 semanas de edad, paja de avena y heno de alfalfa los cuales se clasificaron en tres calidades (alta, media y baja).

Cada forraje (4) fue sometido a la prueba de digestibilidad in vitro con diferentes relaciones de saliva artificial y licor del Compartimento 1 (C) y Compartimento $2\left(\mathrm{C}_{2}\right)$. Estas relacionés fueron: 2:1, $4: 1,6: 1$ y $8: 1$. La relación de $4: 1$ es la relacion usada en la técnica.

Los parámetros evaluados fueron los residuos indigeribles y la digestibilidad de la materia seca. 
La digestibilidad in vitro de la materia seca (DIVMS) utilizada fue la técnica descrita por Tilley y Terry (1963). El método consta de dos etapas:

$1^{\mathrm{a}}$ Etapa: Se utilizaron muestras por duplicado de $0.5 \mathrm{~g}$ de forraje molido y secado a $60{ }^{\circ} \mathrm{C}$ por 24 horas, las que fueron transferidas a tubos de ensayo provistos de válvulas Bunsen. En cada corrida se colocaron dos tubos control sin muestras y dos tubos con muestras de digestibilidad conocidas; con el fin de controlar la actividad microbiana entre corridas. Todos los tubos llevaron $50 \mathrm{ml}$ de la solución licor ruminal de alpaca y saliva artificial Mc Dougall en las diferentes proporciones.

La composición de la saliva artificial en gramos por litro fue la siguiente: $9.8 \mathrm{bi}-$ carbonato de sodio $\left(\mathrm{NaHCO}_{3}\right), 7.0$ Fosfato ácido de sodio $\left(\mathrm{Na}_{2} \mathrm{HPO}_{4} 7 \mathrm{H}_{2} \mathrm{O}\right), 0.57$ Cloruro de potasio (KCL), 0.47 Cloruro de sodio $(\mathrm{NaCl}), 0.04$ Cloruro de calcio $\left(\mathrm{CaCl}_{2}\right), 0.12$ Sulfato de magnesio $\left(\mathrm{Mg} \mathrm{SO}_{4} 7 \mathrm{H}_{2} \mathrm{O}\right)$. Esta solución fue burbujeada vigorosamente con $\mathrm{CO}_{2}$ hasta alcanzar un $\mathrm{pH}$ de 6.7.

El material del compartimento 1 y 2 se colectó a través de una fístula ruminal y se llevó inmediatamente al laboratorio (manteniéndose en baño maría a temperatura de $39^{\circ} \mathrm{C}$ ) El fluido del $\mathrm{C}_{1}$ y $\mathrm{C}_{2}$ se obtuvo fitrando el material del $C_{1} \quad \mathrm{y}_{2}$ a través de cuatro capas de gasa.

Después de agregar la mezcla de saliva artificial (buffer) y licor ruminal, cada tubo se gaseo con $\mathrm{CO}_{2}$ durante 15 segundos. Se incubó a $39^{\circ} \mathrm{C}$ en baño maría por 48 horas. Durante la incubación los tubos fueron mezclados a mano 4 o 5 veces para permitir un ataque homogéneo del forraje por los microorganismos. Después de $\mathbf{4 8}$ horas, la actividad bacterial se detuvo por el agregado de $6 \mathrm{ml}$ de HCL al $20 \%$.

$2^{2}$ Etapa. En esta etapa se le agregó $2 \mathrm{ml}$ de pepsina al 5\%. Los tubos se incubaron por otras 48 horas a $39^{\circ} \mathrm{C}$ con mezclado alterno.
Después de 48 horas los tubos fueron retirados de la incubadora. El residuo insoluble de la muestra fue lavado con agua destilada caliente $\left(90-100^{\circ} \mathrm{C}\right)$; seguidamente se filtró a través de papeles de filtro previamente pesados. Los papeles de filtro con sus respectivas muestras se colocaron a la estufa a $60^{\circ} \mathrm{C}$ por 48 horas, para posteriormente pesarlos y realizar los análisis de datos respectivos.

Para la evaluación de los resultados del experimento se utilizó el diseño irrestricto al azar, con un arreglo factorial A x B, siendo el factor $\mathbf{A}$ los forrajes y el factor $B$ las relaciones saliva artificial: licor ruminal.

En el Cuadro 1 se muestra la composición química de los forrajes utilizados, pudiéndose observar la variación entre forrajes, como es el contenido de fibra cruda, factor que tiene influencia negativa sobre la digestibilidad. Se observa que la paja de avena tiene mayor porcentaje de fibra cruda y menor porcentaje de proteína con respecto a los otros forrajes. El heno de alfalfa posee un mayor porcentaje de proteína, con respecto a los otros forrajes, siendo su porcentaje de fibra cruda relativamente alto.

En el Cuadro 2 al análisis los coeficientes de digestibilidad in vitro de la materia seca (DIVMS), independientemente de la relación de saliva artificial: licor ruminal, se observa diferencias $(P<0.05)$, entre fomajes. Así la paja tiene la menor DIVMS seguida por la alfalfa y ambos inferiores a los rye grass.

La paja presenta una menor DIVMS explicada a su alto contenido de fibra cruda, y presencia de lignina que la hacen resistente al ataque microbiano. Con respecto a esto Mc Donald y Edwards (1986), señalan que la fracción de fibra bruta de un alimento influye negativamente sobre la digestibilidad. 
Cuadro 1. Análisis proximal de los forrajes experimentales (\%, Base Seca).

\begin{tabular}{lcccc}
\hline \multicolumn{1}{c}{ Indice } & Paja de avena & Heno de alfalfa & $\begin{array}{c}\text { Rye grass 6-8 } \\
\text { semanas }\end{array}$ & $\begin{array}{c}\text { Rye grass 3-4 } \\
\text { semanas }\end{array}$ \\
\hline Humedad & 7.7 & 10.47 & 74.67 & 74.03 \\
Materia seca & 92.3 & 89.53 & 25.33 & 25.97 \\
Proteína & 4.99 & 19.31 & 7.04 & 11 \\
Ext. Etéreo & 2.46 & 1.90 & 2.83 & 3.12 \\
Fibra Cruda & 39.03 & 28.77 & 16.61 & 14.08 \\
Extracto libre & 46.75 & 41.10 & 64.48 & 61.71 \\
de nitrógeno & & 8.92 & 8.84 & 10.09 \\
Ceniza & 4.31 & & & \\
\hline
\end{tabular}

El rye grass en sus dos tiempos de corte presentan una digestibilidad similar, debido a que ambos poseen bajo contenido de fibra cruda y al alto porcentaje de carbohidratos solubles que son fácilmente atacados por las enzimas microbianas. (Church, y Pond 1977).

En el Cuadro 2 también puede evaluarse las DIVMS en función a las relacio- nes de saliva artificial: licor ruminal, hallándose diferencias estadísticas significativas $(\mathrm{P}<0.001)$ entre la DIVMS en la relación 8 : 1 con respecto a los otros tratamientos. Esta diferencia puede ser debido a que al incrementarse la concentración de saliva artificial el contenido se diluye y las bacterias no cuentan con un medio adecuado para su desarrollo.

Cuadro 2. Digestibilidad de forrajes de diferente calidad sometidos a diferentes relaciones de saliva: licor ruminal.

\begin{tabular}{lcccccc}
\hline \multirow{2}{*}{ Forrajes } & \multicolumn{6}{c}{ Relación saliva artificial: licor ruminal } \\
\cline { 2 - 7 } Heno de alfalfa & $2: 1$ & $4: 1$ & $6: 1$ & $8: 1$ & Promedio & EMS** \\
\cline { 2 - 7 } Rye grass 3-4 sem. & $70.04^{\mathrm{a}}$ & $\mathbf{6 9 . 9 4 ^ { \mathrm { a } }}$ & $\mathbf{6 9 . 8 0 ^ { \mathrm { a } }}$ & $\mathbf{7 0 . 5 3 ^ { \mathrm { a } }}$ & 70 & 3.6193 \\
Rye grass 6-8 sem. & $87.22^{\mathrm{a}}$ & 84.48 & $\mathbf{8 7 . 1 0 ^ { \mathrm { a } }}$ & $\mathbf{8 4 . 3 6 ^ { \mathrm { a } }}$ & 86 & 3.3886 \\
Paja de avena & 85.73 & 86.55 & 83.05 & 79.16 & 83.6 & 3.4560 \\
Promedio & $54.32^{\mathrm{a}}$ & $53.3^{\mathrm{a}}$ & $53.27^{\circ}$ & $40.36^{\mathrm{b}}$ & 50.3 & 3.1800 \\
\hline
\end{tabular}

Letras diferentes en filas indican diferencias estadísticas significativas $(\mathrm{P}<0.05)$.

** Error estándar de la media.

Son varios los factores que determinan la capacidad buffer del fluido ruminal, siendo uno de ellos la cantidad de saliva secretada por el animal, especialmente durante los procesos de masticación y rumia. La saliva posee un poder altamente alcalino pH 8.37 y actúa de agente neutralizante de los ácidos grasos volátiles formados en el transcurso de la fermentación. Esta propiedad se le confiere a su contenido de sales, tales como bicarbonato de sodio, y en menor grado a los fosfatos de sodio y potasio, los cuales poseen una alta capacidad buffer. 
Al respecto Ortiz (1971), indica que la alpaca posee mayor poder tamponante debido a su alta relación de flujo salival y tamaño de los compartimentos 1 y 2 del estómago, permitiendo una mayor concentración de elementos y compuestos tampones por unidad de volumen del contenido estomacal. Sin embargo Cavero (1970) reporta que los elementos buffer en la saliva parotidea de la alpaca son similares al del ovino. Vallenas y Stevens (1971a); manifiestan que el estómago de los dos primeros compartimentos son más eficientes en la neutralización de los ácidos grasos volátiles, producido por la fermentación microbiana, un aspecto responsable de lo anterior que no tiene punto de comparación con el rumen es la presencia de las bolsas glandulares de los sacos craneal y caudal del primer compartimento del estómago de los camélidos sudamericanos. Eckerlin y Stevens (1973), igualmente manifiestan que la concentración de bicarbonato de los sacos glandulares permite una mayor efecto tampón en el primer compartimento de los camélidos.

Se halló un efecto significativo en la interacción del forraje con las relaciones de saliva artificial: licor ruminal, en la paja con la relación de 8:1. Lo que permite deducir que forrajes con alta fibra son los que se afectan por la alta concentración de saliva.

Los ácidos grasos volátiles (AGV) que se forman por la acción microbiana son productos finales de diversas reacciones intermedias, si por alguna razón estos AGV se acumularan, podrían suprimir o alterar los procesos fermentativos porque disminuyen el pH del $\mathrm{C} 1$ y $\mathrm{C} 2$. Sin embargo, las alpacas mantienen las condiciones necesarias para la fermentación amortiguando los cambios de $\mathrm{pH}$ y retirando los $\mathrm{AGV}$ por medio de la absorción de las paredes mediante un mecanismo más eficiente. Con respecto a la concentración de AGV, Vallenas Y Stevens (1971- b) señalan que no existen mayores diferencias en las concentraciones de estos ácidos con aquellas observados en los vacunos y ovinos.
De los resultados obtenidos en el presente experimento, no obstante las limitaciones propias del sistema in vitro, pueden deducirse que existen otros factores diferentes a la mayor cantidad de bicarbonatos y fosfatos en el $\mathrm{C} 1$ y $\mathrm{C} 2$ que contribuyen a determinar la mayor eficiencia digestiva, entre estos posibles factores podrían mencionarse la mayor motilidad del $\mathrm{C} 1$ y $\mathrm{C} 2$ reportada en la alpaca (Vallenas 1970), la velocidad de pasaje de la ingesta y la capacidad de producción y absorción de AGV.

De las diferentes relaciones saliva: licor del $\mathrm{C} 1$ y C2, para el desarrollo de la técnica de digestibilidad in vitro de alpacas en forrajes de diferentes calidades, sólo la relación 8:1 afectó la digestibilidad del forraje de más baja calidad. Pudiéndose usar relaciones de 2:1 a 6:1 sin que se afecte la estimación de la digestibilidad de la materia seca usando la técnica de digestibilidad in vitro de dos fases.

1. Cavero, J. R. 1970. Composición química de la saliva parotídea de la alpaca (Lama pacos). Tesis Fac. Medicina Veterinaria UNMSM. Lima - Perú, p. 30.

2. Church, D. C. y Pond W. G. 1977. Bases científicas para la nutrición y alimentación de los animales domésticos. 2a ed., p. 45 Editorial Acribia. Zaragoza-España.

3. Cunningham James G., 1995. Fisiología Veterinaria. 2a. ed. Editorial Mc Graw-Hill Interamericana México, p. 350-377.

4. Eckerllin R. H. Y Stevens C. E. 1973. Bicarbonate secretion by the glandular saccules of the llama stomach. Cornell Vet. 63: 436-445. 
5. Mc. Donald P. Y Edwards R. A. 1986. Nutrición animal 3a. ed., pp. 58-70. Editorial Acribia. Zaragoza-España. Mc Dougall, E. I. 1984. Studies on ruminant saliva the composition and out put of sheep saliva. Biochem. J. 43: 99-109.

6. Ortiz, C. F. 1971. Contribución al estudio de la saliva parotídea de la alpaca: pH, Na, $\mathrm{K}$ y Ca. Tesis Prog. Acad. Med. Vet., Univ. Nac. Mayor de San Marcos. Lima - Perú, p. 29.

7. San Martín F., y F. Bryant., 1987. Nutrición de los Camélidos Sudamericanos: Estado de nuestro conocimiento. Artículo técnico T-9-505, pp. 7-28.
8. Tilley, J. M. A. and R. A. Terry. 1963. A two stage technique for the in vitro digestión of forage crops. British Grassland society 18:104-111.

9. Vallenas, A. 1970. Structural and funtional studies of the llama and guanaco stomach. Ph. D. Tesis, Cornell university.

10. Vallenas, A. y C. E. Stevens. 1971a. Volatile fatty acid Concentrations and $\mathrm{pH}$ of llama and guanaco forestomach digesta. Cornell Vet. 61: 239-252.

11. Vallenas, A. y C.E. Stevens. $1971 b$. Volatile fatty acid Concentrations and $\mathrm{pH}$ of llama and guanaco forestomach digesta. Cornell Vet. 61:239-252. 